\title{
COMPARATIVE LIFE CYCLE ASSESSMENT STUDY FOR FABRIC BASED
} ELECTROMAGNETIC SHIELDING

\author{
ION RAZVAN RADULESCU ${ }^{1}$, EMILIA VISILEANU ${ }^{1}$, RAZVAN SCARLAT ${ }^{1}$, \\ CATALIN CONSTANTIN ${ }^{2}$, BOGDANA MITU ${ }^{2}$ \\ ${ }^{1}$ INCDTP - Bucharest, Str. L. Patrascanu 16, 030508 Bucharest, Romania, \\ razvan.radulescu@incdtp.ro,e.visileanu@incdtp.ro, razvan.scarlat@incdtp.ro \\ ${ }^{2}$ INFLPR - Bucharest, Str. Atomistilor 409, 077125 Bucharest, Romania, \\ catalin.constantin@inflpr.ro,mitu.bogdana@inflpr.ro
}

\begin{abstract}
Life Cycle Assessment (LCA) studies represent the scientific approach for elaborating modern policies and supporting management decisions in the field of Sustainable Production and Consumption. The goal of many LCA studies undertaken for research are related to an exhaustive comparison of a modern, innovative product or process with respect to an initial, conventional one. This paper deals with such an approach for fabric based electromagnetic shielding. Electrically conductive textile fabrics are used in applications of electromagnetic shielding. Two basic types of technology for imparting electro- conductive properties to textiles are available, namely: insertion of conductive yarns in the fabric structure and coating with conductive layers. Magnetron plasma coating is a modern technology for achieving thin metallic layers on fabrics. Therefore, we focused the LCA study to the comparison between cotton woven fabrics with inserted conductive yarns out of stainless steel in warp and weft direction and cotton fabrics coated with thin layers of copper by magnetron plasma laboratory equipment. Functional unit of the comparative study was one square meter of EM textile shield with $5.2 \mathrm{~dB}$ at $1 \mathrm{GHz}$. A modelling of the fabric with inserted conductive yarns was performed in order to reach same shielding effectiveness at a certain frequency, as in the case of the coated fabric. Inventory data was collected for the fabric with conductive yarns from the textile company SC Majutex SRL, while for the plasma coated fabric from INFLPR. Impact assessment was performed by INCDTP, by using the LCA software SimaPro7 and the data basis EcoInvent 3.0. Interpretation of results shows that weaving of conductive yarns has a smaller impact on the environment than magnetron plasma coating using laboratory equipment, in a ratio of 1:2. This fact is explained by the industrial process of weaving as compared to laboratory process of coating, whereas brings the idea that upon utilization of industrial magnetron equipment for coating one may achieve in the end better environmental impact due to the process optimization for large area plasma processing.
\end{abstract}

Keywords: LCA, EMI shielding, fabrics

\section{INTRODUCTION}

Electromagnetic (EM) shielding is especially relevant in nowadays radiation polluted environment (Paul, 2006). This is a field belonging to Electromagnetic Compatibility (Schwab and Kuerner, 2013). Textile materials with electrical conduction properties are suitable for EM shielding due to their flexibility, low weight and good mechanical resistance as well as due to the tailored design for end user requirements property (Neruda and Vojtech, 2018; Radulescu et al., 2018a; Radulescu et al., 2018b). There are two types of technologies for imparting electric conductive properties to textile materials: insertion of conductive yarns in the fabric structure and coating with conductive layers (Ziaja and Jaroszewski, 2011). Modern coating technologies, such as magnetron plasma coating are recently used to achieve textile electromagnetic shields (Koprowska et al., 2004).

Life Cycle Assessment (LCA) is an instrument to quantify the impact on the environment for a specific product or process (Kloepffer, 2014). LCA studies are used to foster decisions for implementing new technologies on management level of SMEs (Wolf et al., 2010). LCA studies may be conducted for various reasons, such as: 
benchmarking of various products, identifying Key Environment Performance Indicators (KEPI), motivating green acquisitions or comparative assessment between a modern and a conventional technology. Latter reason is used mainly for research, to prove the environmentally friendly character of a modern technology.

Several LCA studies were accomplished in the scientific literature for textile products and processes. Research was accomplished on LCA studies for textile raw materials, namely cotton, polyester, nylon, acryl and elastane within a benchmarking study (Van der Velden et al., 2014). Research was directed towards LCA for various treatment processes on textiles, such as the fireproof treatment of fabrics and its environment impact reduction by eco-path disposal treatment (Pesnel and Perwuelz, 2011). Three different methods of recycling PES trousers (chemical/ mechanical and energy recovery) were analyzed in (Yasin et al., 2018). Moreover, attention was focused on LCA for smart and e-textiles with conductive fibers made of conjugated polymers, carbon nanotubes, graphene, polymer blend or nanocomposite (Lund et al., 2018). Ecodesign in case of smart textiles plays an important role: a comparative LCA study for eco-designed and original smart textiles products was achieved in (Van der Velden et al., 2015). End-of-life and recycling management of the textile chain was analyzed by LCA in countries, such as Finland (Dahlbo et al., 2017) and Denmark (Koligkioni et al., 2018). A review for the overall impact of nanomaterials on the environment was performed in (Miseljic and Olsen, 2014).

Main aim of this paper is to conduct a comparatively LCA study for electromagnetic shields made of woven fabrics with conductive yarns and shields made of plasma coated fabrics, in order to analyze the environmentally friendly character of plasma processing.

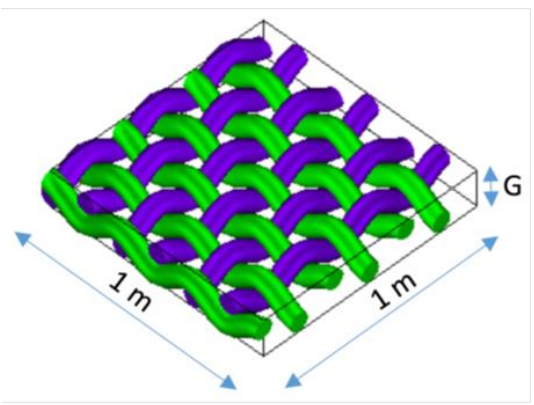

Figure 1. Woven fabric with inserted stainless steel yarns

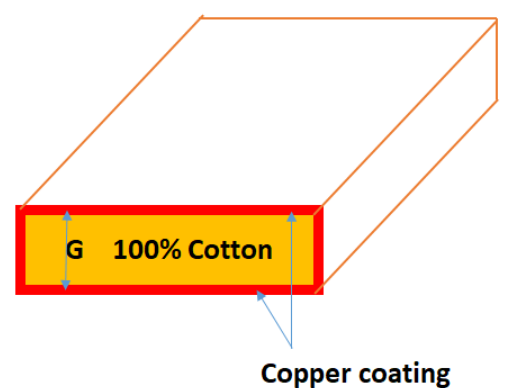

Figure 2. Woven fabric with Copper coating

Secondary aim is to evidence the improved environment performance of a modern magnetron sputtering plasma equipment with deposition rate of $100 \mathrm{~nm} / \mathrm{min}$ compared to an initial plasma equipment with deposition rate of $9 \mathrm{~nm} / \mathrm{min}$. 


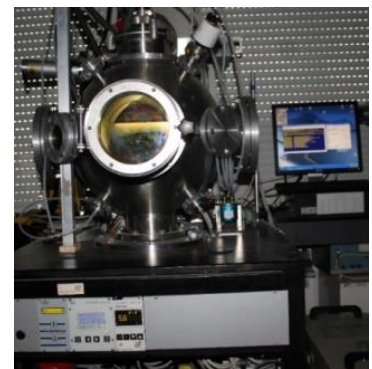

Figure 3. Modern magnetron plasma equipment

The LCA study was conducted according to the standard ISO 14040 on four phases: Goal and Scope definition, Life Cycle Inventory (LCI), Life Cycle Impact Assessment (LCIA) and Interpretation. It tackled the recommendations of the ILCD Handbook. The LCA study is a cradle-to-gate study. Following LCI data was applied with following limitations:

- LCI data applied: consume of raw materials, natural resources, auxiliary chemical substances, electrical energy on equipment and emissions to air;

- Limitations: consume of heat (gas / coal), as equivalent for both types of processes, distribution, storage and recycling of materials.

The method EcoIndicator99 (E) was used for the study with the impact categories: carcinogens, respiratory organics, respiratory inorganics, climate change, radiation, ozone layer, ecotoxicity, acidification / eutrophication, land use, minerals, fossil fuels. These impact categories may be divided in three groups: Humans health, Quality of ecosystem and Resource depletion.

\section{MODELLING OF THE WOVEN FABRIC STRUCTURE}

The functional unit of the electromagnetic shield was set to 1 sqm of textile fabric with $5.2 \mathrm{~dB}$ at $1 \mathrm{GHz}$. The electromagnetic shielding effectiveness (EMSE) of both types of textile shields was determined experimentally by TEM cell, according to the standard ASTM ES-07:

- The plasma coated cotton fabric with Copper on both sides of the material with the thickness of $t=400 \mathrm{~nm}$ had an EMSE of $5.2 \mathrm{~dB}$ at $1 \mathrm{GHz}$

- The cotton fabric with inserted conductive stainless steel yarns and a grid with the distance $\mathrm{a}=4 \mathrm{~mm}$ had an EMSE of $24 \mathrm{~dB}$ at $1 \mathrm{GHz}$

The distance of the grid formed by conductive yarns was modelled according to analytical relations (Neruda and Vojtech, 2018), in order the woven fabric with stainless steel yarns should have same EMSE of $5.2 \mathrm{~dB}$ at $1 \mathrm{GHz}$, as the plasma coated fabric.

The following analytic relations were used for calculation of the grid distance:

$$
E M S E=20 \log \left(\frac{\lambda / 2}{a \sqrt{\pi}}\right)
$$

$a=\frac{\lambda}{2 \sqrt{\pi}} \times 10^{-\frac{E M S E}{20}}$

with following notations:

$E M S E$ = electromagnetic shielding effectiveness, in this case EMSE was set to $5.2 \mathrm{~dB}$

https://doi.org/10.24264/icams-2020.IV.18 
$\lambda$ - wave length of the incident EM radiation, in this case frequency $=1 \mathrm{GHz}$ and $\lambda=30$ $\mathrm{cm}$ $a$ - distance of the grid formed by the conductive yarns of the woven fabric

As such, the distance of the grid formed by conductive yarns was enlarged, by keeping same fabric density and achieving a corresponding lower content of stainless steel per sqm of fabric.

Figure 4 shows the Matlab diagram for relation (2) - the distance of the grid for the frequency domain of 0.1-10 GHz in logarithmic scale.

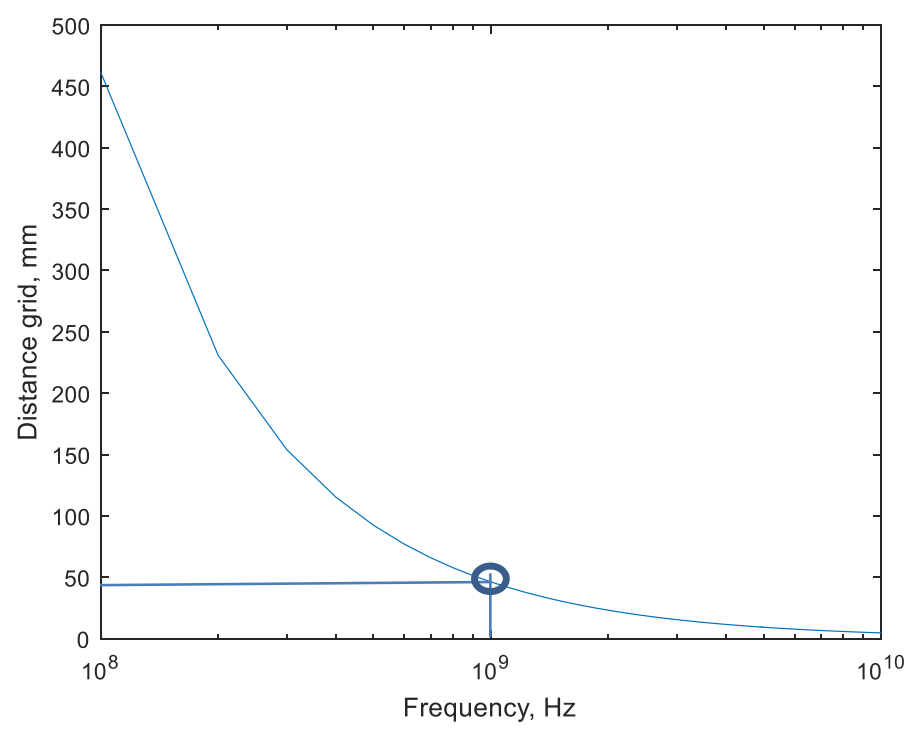

Figure 4. Distance of grid related to frequency for $\mathrm{EMSE}=5.2 \mathrm{~dB}$

According to calculation it resulted a modelled distance of $\mathrm{a}=46 \mathrm{~mm}$ between conductive yarns, by keeping same fabric density and yarn fineness, namely fabric structure: warp fabric density $=180$ yarns $/ 10 \mathrm{~cm}$, weft density $=170$ yarns $/ 10 \mathrm{~cm}$ with yarn fineness Nm50/2 both for cotton and stainless steel yarns.

\section{LCI, LCIA AND INTERPRETATION}

The following LCI data were considered for the cotton fabrics with inserted stainless steel yarns:

- Electric energy consumption for spinning the stainless-steel yarn with mean values from the literature (Van der Velden et al., 2014);

- $\quad$ Electric energy consumption for spinning of cotton (EcoInvent3.0 data base)

- Electric energy consumption for cotton weaving (data from industrial company SC Majutex SRL)

- Raw material consumption of cotton and stainless steel (according to the fabric's specific mass of $143 \mathrm{~g} / \mathrm{sqm})$

- $\quad$ Emissions of heat into the air (EcoInvent3.0 data base) 
Figure 5 shows within a weighting diagram the environmental impact with respect to eleven categories (impact related to a common reference), for the woven fabric with inserted stainless steel yarns.

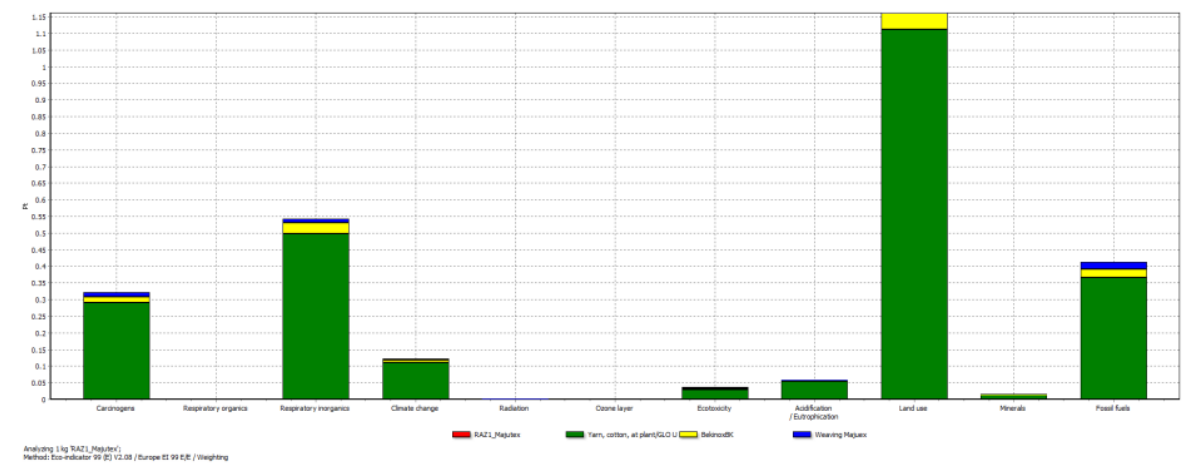

Figure 5. Weighting diagram for woven fabric with conductive yarns

Land use is the most addressed impact category, a fact explained by cultivation of cotton raw material. Respiratory organics and carcinogens may be explained by the emissions to air of the weaving process. Fossil fuels impact category is addressed by electric energy consumption.

The following LCI data were considered for the copper coated cotton fabrics:

- Electric energy consumption for plasma equipment, including vacuum pumps and pressure control systems, mass flow controllers, RF generator and matching box, PC (data from INFLPR);

- Raw material consumption: cotton fabric, copper, argon (data from Majutex and INFLPR);

- Emissions into the air: argon (data from INFLPR).

Figure 6 shows the environmental impact within a weighting diagram upon the same categories as previous, for the copper plasma coated woven fabric.

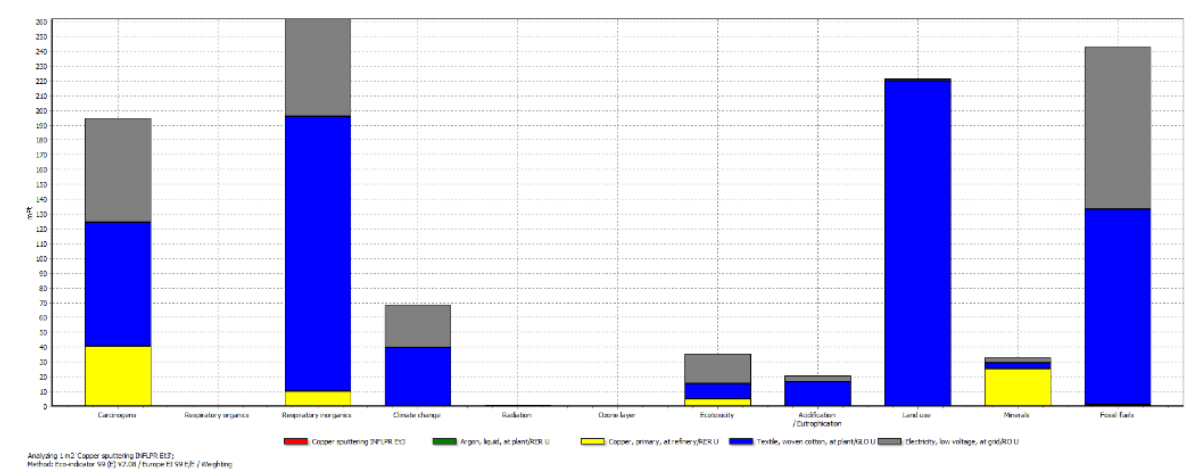

Figure 6. Weighting diagram for plasma coated fabric

Figure 6 evidenced that the most addressed impact categories are those related to respiratory inorganics in conjunction with emissions of Argon, Fossil fuels because of 
electric energy consumption and Land use originating from cotton cultivation for the raw fabric. Figure 7 shows the comparative single score diagram between the impact of the woven fabrics with conductive yarns and the plasma coated fabric.

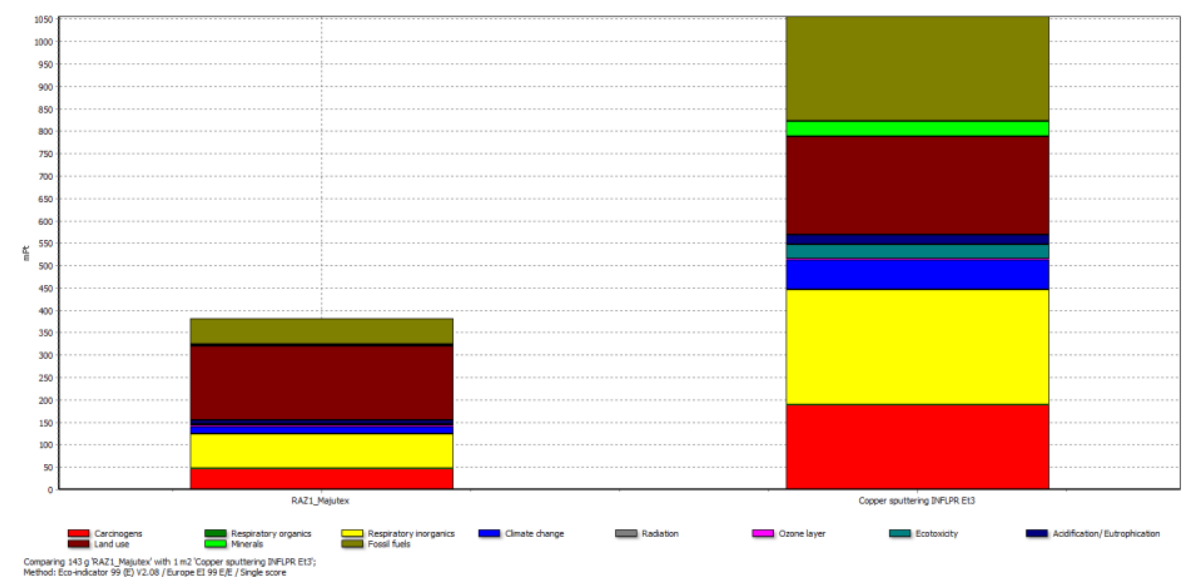

Figure 7. Comparative single score diagram for woven fabrics with conductive yarns (left) and plasma coated fabrics (right) - Fabric mass $=143 \mathrm{~g} / \mathrm{sqm}$

The overall impact indicator of the plasma coated fabrics is of $1050 \mathrm{mPt}$ while the indicator of fabrics with conductive yarns is of $380 \mathrm{mPt}$. The ratio is of $1: 2.76$, which means impact of plasma coated fabrics is 2.76 times higher than impact of woven fabrics with conductive yarns.

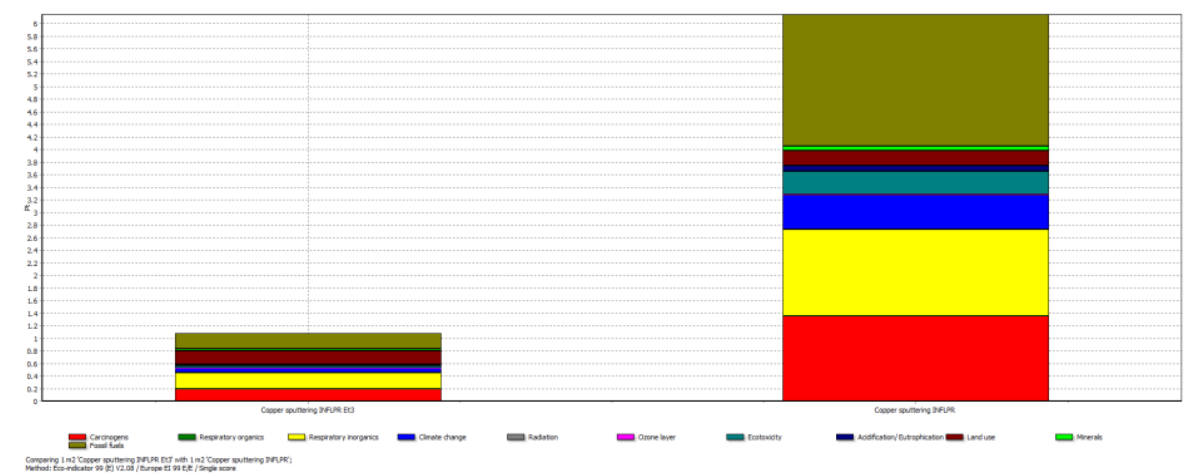

Figure 8. Comparative single score diagram for plasma coated fabrics with modern equipment (left) and conventional equipment (right)

Figure 8 is a single score diagram showing the impact for the modern plasma equipment with deposition rate of Copper $100 \mathrm{~nm} / \mathrm{min}$ and the conventional plasma equipment with deposition rate of $9 \mathrm{~nm} / \mathrm{min}$. The reduced impact in case of the modern equipment is mainly due to savings in energy consumption for shorter process time, as well as the implementation of recirculation for water cooling system. The overall impact 
indicator for the modern plasma equipment is $1.05 \mathrm{Pt}$, while for the conventional plasma equipment is $6.2 \mathrm{Pt}$. This indicates a ratio of 1:6 between the impact of coating by the two types of plasma equipment.

\section{CONCLUSION}

An industrial process of weaving was comparatively assessed with a laboratory process of plasma coating for production of textile electromagnetic shields. Plasma coating with metals (Copper) is an advanced technique of rendering electroconductive properties to fabrics and has multiple advantages: the nanometer coating enables a good flexibility of the fabric, thickness of coating may be precisely designed and adapted to end-user requirements. Method EcoIndicator $99 \mathrm{E}$ was applied and related impact diagrams were generated within software SIMAPRO7.

LCA was conducted by considering main consumption data during production stage - Cradle-to-gate study. LCI data covered consumption of electric energy, raw materials gas and emissions to air. The impact on the environment was according to single score diagram 2.76 times higher in case of plasma coating compared to weaving of conductive yarns. Same functional unit was ensured by modelling the fabric with inserted conductive yarns: 1 sqm of textile shield with $5.2 \mathrm{~dB}$ at $1 \mathrm{GHz}$.

As such, the LCA study has an indicative character in comparison of weaving and plasma coating. LCAs on conductive fabrics are in early stage of research, while this study is tackling the modern technology of plasma coating.

\section{Acknowledgment}

Research work for this study was supported by a grant of CCDI-UEFISCDI project number COFUND -MANUNET III - TexEMFiRe, contract 28/2018.

Publishing has been funded by Ministry of Research and Innovation, by Program $1-$ Development of the national system for research-development, Subprogram 1.2 Institutional performance - projects for funding excellence in RDI, contract no. 6PFE from 16.10.2018.

\section{REFERENCES}

Dahlbo, H., Aalto, K., et al. (2017), "Increasing textile circulation-Consequences and requirements", Sustainable Production and Consumption, 44-57, https://doi.org/10.1016/j.spc.2016.06.005.

Kloepffer, W. (editor) (2014), Background and Future Prospects in Life Cycle Assessment, Springer, Dordrecht, ISSN 2214-3513, https://doi.org/10.1007/978-94-017-8697-3.

Koligkioni, A., Parajuly, K., et al. (2018), "Environmental assessment of end-of-life textiles in Denmark", Procedia CIRP, 69, 962 - 967, https://doi.org/10.1016/j.procir.2017.11.090.

Koprowska, J. et al. (2004), "New type textiles with shielding properties", Fibres \& Textiles in Eastern Europe, 12, 39-42.

Lund, A., Van der Velden, N., Persson, N-K. et al. (2018), "Electrically conducting fibres for e-textiles: An open playground for conjugated polymers and carbon nanomaterials", Materials Science \& Engineering $R, 126,1-29$, https://doi.org/10.1016/j.mser.2018.03.001

Miseljic, M. and Olsen, S. (2014), "Life-cycle assessment of engineered nanomaterials: a literature review of assessment status", J Nanopart Res, 16, 2427, https://doi.org/10.1007/s11051-014-2427-x.

Neruda, M. and Vojtech, L. (2018), "Electromagnetic shielding effectiveness of woven fabrics with high electrical conductivity: complete derivation and verification of analytical model", MDPI - Materials, 11, 1657, https://doi.org/10.3390/ma11091657.

Paul, C. (2006), Introduction to Electromagnetic Compatibility, WILEY Interscience, ISBN-13: 978-0-47175500-5.

https://doi.org/10.24264/icams-2020.IV.18 


\section{Comparative Life Cycle Assessment Study for Fabric Based Electromagnetic Shielding}

Pesnel, S. and Perwuelz, A. (2011), "LCA: a decision-making tool for recycling process in textile industry", https://docplayer.net/24614249-Lca-a-decision-making-tool-for-recycling-processes-in-textile-industry.html

Radulescu, I.-R., Costea, M., et al. (2018a), "Web application for predicting the shielding effectiveness of woven fabrics with conductive yarns", U.P.B. Sci. Bull., Series C, C(4), ISSN 2286-3540.

Radulescu, I.-R., Surdu, L. et al. (2018b), "Modelling and testing the electromagnetic near field shielding effectiveness achieved by woven fabrics with conductive yarn", Industria Textila, 3, 169-176, https://doi.org/10.35530/IT.069.03.1508.

Schwab, A. and Kuerner, W. (2013), Electromagnetic Compatibility, AGIR Publishing House, ISBN: 978 973-720-359-5.

Van der Velden, N., Patel, M. et al. (2014), "LCA benchmarking study on textiles made of cotton, polyester nylon, acryl or elastane", Int. J. Life Cycle Assess, 19, 331-356, https://doi.org/10.1007/s11367-013-0626-9.

Van der Velden, N.M., Kuusk, K. and Koehler, A. (2015), "Life cycle assessment and eco-design of smart textiles: The importance of material selection demonstrated through e-textile product redesign", Materials and Design, 84, 313-324, https://doi.org/10.1016/j.matdes.2015.06.129.

Wolf, M.-A., Pant, R. et al. (2010), ILCD Handbook - The International reference Life Cycle Data system, Joint Research Centre, ISBN 978-92-79-19092-6, https://doi.org/10.2788/38479.

Yasin, S., Behary, N. and Perwuelz, A. (2018), "Life cycle assessment of flame retardant cotton textiles with optimized end-of-life phase", Journal of Cleaner Production, 172, 1080-1088, https://doi.org/10.1016/j.jclepro.2017.10.198

Ziaja, J. and Jaroszewski, M. (2011), "EMI shielding using composite materials with plasma layers", in Vitaliy Zhurbenko (ed.), Electromagnetic Waves, InTechOpen https://doi.org/10.5772/16553. 